ZalǫcZnilf

DOI 10.21697/zk.2021.8.05

\title{
METAFORA „WIEDZA TO WIDZENIE” W RÓŻNYCH SYSTEMACH SEMIOTYCZNYCH I DYSKURSACH
}

WERONIKA LIPSZYC

\author{
Wydział Polonistyki UW \\ Faculty of Polish Studies, University of Warsaw \\ w.lipszyc@uw.edu.pl \\ ORCID: 0000-0001-6210-9018
}

Znacząca rola wzroku w globalizującej się kulturze Zachodu wynika zarówno z kulturowego dziedzictwa, jak i ze specyfiki współczesnej przestrzeni medialnej, zdominowanej przez obrazy. Badacze kultury wizualnej wskazują, że dotyczy ona nie tylko tego, co poznawane przez zmysł wzroku chodzi o „pole wizualne” w obszarze różnych praktyk kultury. Jest to, jak pisze Iwona Kurz, „dynamiczna przestrzeń relacji między podmiotem a rzeczywistością, przez obraz zapośredniczana lub w nim wyrażana, obszar gęsty od tekstów, dyskursów, technik i praktyk, dynamiczny i znaczeniowo "mnogi«"'. W ramach kultury wizualnej badaniu podlegają więc nie tylko obrazy, ale też ich odbiór, oddziaływanie, dyskursy wytwarzane przez nie i wokół nich w różnych kodach semiotycznych i mediach. Tu także należałoby sytuować rozważania dotyczące metafor związanych $\mathrm{z}$ wizualnością.

„Metafora to w pierwszym rzędzie zjawisko natury kognitywnej” zauważa Teresa Dobrzyńska. „W procesie sensotwórczym uruchomionym poprzez użycie metafory zachodzi wyobrażanie sobie czegoś w pewien szczególny sposób, a polega to przede wszystkim na tworzeniu nowych konfiguracji pojęciowych, na projekcji cech"3. Badaczka wskazuje, że nawet wówczas, kiedy akty metaforyzacji łączą się z aktami percepcji, np. wzrokowej, mają przede wszystkim charakter przekształceń pojęciowych.

${ }^{1}$ I. Kurz, Posłowie, [w:] J. Crary, Zawieszenia percepcji. Uwaga, spektakl i kultura nowoczesna, tłum. Ł. Zaremba, I. Kurz, red. I. Kurz, Warszawa 2009, s. 471.

2 T. Dobrzyńska, Od słowa do sensu. Studia o metaforze, Warszawa 2012, s. 101.

3 Ibidem. 
Metaforyzowanie zaś to proces konieczny, aby pojęcia abstrakcyjne przybliżyć konkretnym doświadczeniom. Jak stwierdza Hannah Arendt: „Język, dzięki swemu metaforycznemu użyciu, umożliwia nam myślenie, czyli kontakt $\mathrm{z}$ kwestiami niezmysłowymi, ponieważ pozwala na przenoszenie, metapherein, naszych doświadczeń zmysłowych. Nie ma dwóch światów, ponieważ metafora je unifikuje" ${ }^{4}$. Język, poprzez warstwę figuratywną, jest więc zakorzeniony w doświadczeniu zmysłowym - owe dwa światy się przenikają.

Łączenie doświadczenia zmysłowego i poznania tego, co inteligibilne, jest istotą metafory „wiedza to widzenie”. Wyłaniają się tu dwa pola problemowe: kwestia obecności wymienionej konstrukcji w poszczególnych systemach semiotycznych oraz jej roli w różnych dyskursach.

\section{WIEDZIEĆ TO WIDZIEĆ - WIDZIEĆ TO WIEDZIEĆ?}

Metafora „wiedza to widzenie”, ujmująca nabywanie i przekazywanie wiedzy w kategoriach zjawisk wzrokowych, należy do konstrukcji niezwykle rozpowszechnionych, ugruntowanych i zleksykalizowanych. Związek tych dwóch pojęć nie prowadzi obecnie do wyłonienia się nowego znaczenia, zazwyczaj metaforyczność konstrukcji w ogóle nie jest zauważana. Jak wskazują ustalenia badaczy języka, „[n]iemal wszystkie czasowniki określające postrzeganie wzrokowe bywają również używane do oznaczania aktywności intelektualnej człowieka (chociaż nie zawsze jest to odnotowane przez słowniki)"6; co więcej, znaczenie mentalne (widzieć - 'poznawać, uświadamiać

${ }^{4}$ H. Arendt, Życie umysłu, tłum. H. Buczyńska-Garewicz, R. Piłat, B. Baran, Warszawa 2016, s. 108.

5 Posługuję się formułą "wiedza to widzenie" zaczerpniętą ze znanej pracy George'a Lakoffa i Marka Johnsona Metafory w naszym życiu (G. Lakoff, M. Johnson, Metafory $w$ naszym życiu, tłum. i wstęp T.P. Krzeszowski, Warszawa 2010), opublikowanej po raz pierwszy w roku 1980; tam w pisowni: „WIEDZA TO WIDZENIE” (UNDERSTANDING IS SEEING). Określenie „wiedza to widzenie” odnoszę również do wcześniejszych konceptualizacji łączących wiedzę i wzrok.

6 A. Pajdzińska, Wrażenia zmysłowe jako podstawa metafor językowych, „Etnolingwistyka” 1996, nr 8, s. 115. 
sobie’) zdobywa przewagę nad fizycznym (widzieć - 'postrzegać')"’. Choć przezroczysta ${ }^{8}$ dla większości użytkowników języka metafora „wiedza to widzenie” już od kilku dziesięcioleci jest dekonstruowana przez badaczy, zarówno jako wyrażenie językowe, jak i konstrukt pojęciowy. Na gruncie filozofii poddawali ją analizie m.in. Hannah Arendt i Richard Rorty ${ }^{9}$, zaś Jonathan Crary i Martin Jay wskazywali na związki konceptualizacji obecnych w filozofii z innymi dziedzinami kultury, a także z rozwojem nauki i techniki ${ }^{10}$.

Arendt następująco przedstawia mechanizm powstania metafory „wiedza to widzenie":

Wiemy, że pojęcia noeomai ('noume') początkowo używano w sensie percepcji wizualnej; potem nabrało ono sensu percepcji umysłowej jako „rozumienia”, aż wreszcie stało się nazwą najwyższej formy myślenia. Nikt, jak można przypuszczać, nie sądził, że oko, organ wzroku, i nous, organ myślenia, są tym samym, lecz samo słowo wskazywało, że relacja między okiem a widzianym przedmiotem jest podobna do relacji między umysłem a jego przedmiotem myślowym - zapewnia ten sam rodzaj oczywistości ${ }^{11}$.

Ewolucja zakresu znaczenia słowa jest wyrazem przekonania o bliskości obu rodzajów poznania oraz o oczywistości i jasności wiedzy oferowanej przez poznanie wzrokowe - to właśnie sens metafory „wiedza to widzenie”.

7 J. Bartmiński, S. Niebrzegowska-Bartmińska, Dynamika punktu widzenia w języku, tekście i dyskursie, [w:] J. Bartmiński, Językowe podstawy obrazu świata, Lublin 2012, s. 112.

8 Problem przezroczystości widzenia analizuję dokładniej w tekście: W. Lipszyc, Przezroczystość widzenia. Metaforyka wizualna i dyskurs wzrokocentryczny, [w:] Przezroczystość w kulturze, red. A. Smaga, B. Pawłowska-Jądrzyk, Warszawa 2019.

9 Zob. H. Arendt, op. cit.; R. Rorty, Filozofia a zwierciadło natury, tłum. M. Szczubiałka, Warszawa 1994.

10 Zob. J. Crary, Techniques of the Observer. On Vision and Modernity in the Nineteenth Century, Cambridge 1992; idem, Zawieszenia percepcji. Uwaga, spektakl $i$ kultura nowoczesna, tłum. Ł. Zaremba, I. Kurz, red. I. Kurz, Warszawa 2009; M. Jay, Downcast Eyes. Denigration of Vision in Twentieth-Century French Thought, Berkeley 1993.

${ }^{11}$ H. Arendt, op. cit., s. 104. 
Z czasem jednak zmienił się kierunek oddziaływania wewnątrz przenośni. Już nie bezpośredniość i ewidentność poznania wzrokowego pozwalała przedstawić, w jaki sposób umysł poznaje rzeczywistość abstrakcyjną, ale wyobrażenie o tym, jak przebiega proces rozumienia zaczęło przekładać się na ocenę widzenia i wzroku. Ciekawym przykładem odwrócenia tej zależności są renesansowe teorie malarskie, ujmujące oko jako doskonały przyrząd pozwalający poznać i wiernie odtworzyć wizualną rzeczywistość, lekceważące dostępną w owej epoce wiedzę dotyczącą fizjologii wzroku oraz ograniczenia medium malarstwa.

Dyskurs oparty na wyobrażeniu umysłu jako oka - doskonałego aparatu poznawczego, a nie fizjologicznego organu - Martin Jay określa jako wzrokocentryzm $^{12}$. Analizowana przez Lakoffa i Johnsona metafora „wiedza to widzenie” zdaje sprawę z zakodowanych w kulturze przekonań charakterystycznych dla wzrokocentryzmu, łączących dobre warunki widzenia z możliwością zdobywania wiedzy.

„Wiedza to widzenie” jako jedna z podstawowych metafor epistemologicznych ${ }^{13} \mathrm{w}$ naszej kulturze ma również charakter postulatywny. Nie tylko przywołuje wspomnianą analogię widzenia i nabywania wiedzy, ale i stawia wymóg: rozumienie powinno nawiązywać z przedmiotem poznania relację tak bezpośrednią, jak oko $\mathrm{z}$ widzianym przedmiotem, dobra wiedza jest tak powszechna i intersubiektywna jak widzenie. Aksjologiczny wymiar metafory spowodował odwrócenie kierunku przenoszenia jakości w jej ramach, a stopniowo doprowadził do kresu jej hegemonii (opisywanego przez Jaya jako kryzys tradycyjnej władzy wzroku) oraz umożliwił dekonstrukcję tej metafory w tekstach kultury i konceptualizacjach teoretycznych.

Jak zauważa Arendt, „[w]szystkie terminy filozoficzne są metaforami, jakby skostniałymi analogiami, a ich rzeczywisty sens ujawnia się, gdy sięgamy do ich oryginalnego kontekstu, który musiał być żywy w umyśle pierwszego filozofa używającego tych pojęć”14. Metafora „wiedza to widzenie”, choć cały czas intensywnie używana, przez długi czas pozostawała martwa, dopiero krytyczny opis przywrócił ją do życia. Rozwój wiedzy na

12 M. Jay, op. cit.

13 Zob. U. Eco, Dzieło otwarte, tłum. J. Gałuszka, L. Eustachiewicz, A. Kreisberg, M. Oleksiuk, Warszawa 1994, s. 165.

14 H. Arendt, op. cit., s. 103. 
temat optycznego i neurologicznego wymiaru widzenia oraz przemiany ikonosfery w XIX wieku spowodowały kryzys dyskursu opartego na tej metaforze, robiąc miejsce dla nowych - odnoszących się do innych zmysłów - konceptualizacji poznania i wyzwolonego od wpływu omawianej przenośni myślenia o wzroku. Także współczesne przemiany rzeczywistości wizualnej, przede wszystkim mediatyzacja i wirtualizacja wizualności, każą zadawać pytania o losy tej konstrukcji i jej znaczenie. Analizy relacji metafor zakorzenionych w wizualności oraz $\mathrm{w}$ innych sposobach doświadczania świata pozwalają przywrócić wzrokowi indywidualną wartość poznawczą ${ }^{15}$, stąd zasadne wydaje się zadanie pytania o obecność metafory „wiedza to widzenie" w różnych systemach semiotycznych oraz dyskursach konstytuujących współczesną kulturę.

\section{METAFORA „WIEDZA TO WIDZENIE” W SZTUKACH WIZUALNYCH}

Metafora „wiedza to widzenie” z racji specyfiki percepcyjnej wydaje się w naturalny sposób obecna w sztukach opartych na wizualności, które aby przekazać wiedzę, muszą utworzyć obraz. Można wyróżnić cały szereg operacji, które służą lepszej widzialności, mimetyczności, iluzyjności obrazu, jak np. perspektywa geometryczna, centralna pozycja ukazywanego obiektu, szczegółowość i wyraźność przedstawienia - wskazują one, że powinniśmy zdobyć jak najwięcej informacji o tym, co ukazane, że im lepiej zobaczymy, tym więcej się dowiemy. Warto zauważyć, że opisane tu operacje, w ramach wzrokocentryzmu utożsamiane z naturalnym widzeniem za pomocą zdrowych oczu, są sztucznymi zabiegami, mającymi na celu wytworzenie nie naturalnego, ale optymalnego widzenia ${ }^{16}$ - to przykład logiki obecnej w metaforze „wiedza to widzenie”.

15 Wiele poruszonych w powyższym podrozdziale zagadnień, w tym problem wzrokocentryzmu i jego kryzysu, zostało obszernie omówionych w przygotowywanej do publikacji pracy Kryzys tradycyjnej władzy wzroku w polskiej literaturze i polskim malarstwie na przełomie XIX i XX wieku.

${ }^{16} \mathrm{Na}$ temat wizualnego kodu semiotycznego zob. S. Wysłouch, Zacznijmy od fundamentów: jeden czy dwa systemy prymarne?, [w:] idem, Literatura i semiotyka, Warszawa 2001. 
Wzrok bywa używany także jako znak wiedzy, zaznacza obecność obserwującego i charakteryzuje instancję poznawczą.

Nader znamienny jest fakt, że w dawnym malarstwie dawano niekiedy symboliczne przedstawienie czyichś oczu, jak gdyby w żaden sposób nie związanych z ogólną kompozycją obrazu. To zjawisko spotykamy w sztuce egipskiej, antycznej, a wreszcie w malarstwie średniowiecznym. Wydaje się możliwe, że oczy te mają symbolizować punkt widzenia pewnego abstrakcyjnego widza wewnątrz obrazu (w pewnych wypadkach można go utożsamiać z Bożym Obserwatorem), z którego pozycji przedstawiony jest właśnie dany obraz ${ }^{17}$.

Ukazanie spojrzenia w formie symbolicznego obrazu oczu lub wzroku konkretnej postaci zwraca uwagę widza na to, kto, jak i na co patrzy, może więc stanowić wzorzec postawy percepcyjnej i odbiorczej. Przykładem jest obraz Albrechta Dürera Święto Różańcowe z 1506 roku z autoportretem malarza. Wzrok postaci skierowany w stronę widza obrazu, jakby poza świat przedstawiony na płótnie, zdaje się nieść wiedzę o umowności reprezentacji i obecności odbiorcy. W Olimpii Eduarda Maneta oczy bohaterki zwrócone ku widzowi są jedną z przyczyn skandalizującej wymowy obrazu: chodzi tu o wykroczenie poza tradycyjne wyobrażenie kobiety jako ciała poddającego się biernie męskiemu spojrzeniu i wyobrażeniu ${ }^{18}$. Wszelkie zabiegi służące tematyzacji i konceptualizacji procesu widzenia zdają się aktualizować metaforę „wiedza to widzenie”, wskazując na utożsamienie dobrej widzialności i pełnej wiedzy. Także te rodzaje przedstawienia, które stawiają opór wzrokowi, nie dają pełnego dostępu do treści obrazu, przywołują problem poznania uzależnionego od możliwości zmysłowego opanowania tego, co ukazane - np. obrazy anamorficzne, obrazy zawierające ukryte, istotne dla interpretacji szczegóły.

Istotność analizowanej metafory wydaje się oczywista także w tych sztukach czy mediach, które - mając charakter polisemiotyczny czy

${ }_{17}$ B. Uspieński, Strukturalna wspólnota różnych rodzajów sztuki (na przykładzie malarstwa i literatury), tłum. Z. Zaron, [w:] Semiotyka kultury, wybór i oprac. E. Janus, M.R. Mayenowa, Warszawa 1977, s. 181.

18 Zob. L. Nead, Akt kobiecy. Sztuka, obscena i seksualność, tłum. E. Franus, Poznań 1998. 
multimedialny - bazują na percepcji wzrokowej, jak np. film czy teatr. W mocy pozostawałyby ustalenia odnoszące się do funkcjonowania kodu wizualnego na gruncie malarstwa: zarówno zabiegi zapewniające jak najlepszą widzialność ukazywanej rzeczywistości, jak i te, które dostęp do niej utrudniają, można uznać za aktualizujące metaforę „wiedza to widzenie”. W filmie używanie widzenia jako metafory dla wiedzy wydaje się nieodzowne, zwłaszcza w przypadku narracji prowadzonej z punktu widzenia postaci ${ }^{19}$. Subiektywna perspektywa może być kreowana również poprzez wykorzystanie innych kodów semiotycznych: monologu wewnętrznego czy specyficznego ukształtowania warstwy audialnej, jednak to punkt widzenia (zyskujący dosłowny sens jako ujęcie z pozycji, w której znajduje się konkretna postać) czy zapis osobliwości percepcyjnych, wskazują na szczególny rodzaj sensualnej i poznawczej relacji ze światem.

Sztuki tradycyjnie zaliczane do plastycznych czy wizualnych, takie jak rzeźba i architektura ${ }^{20}$, odbierane są przede wszystkim za pomocą zmysłu wzroku, choć przywołują także doświadczenia innych zmysłów. Jednak również w przypadku posługiwania się wieloma zmysłami jeden może zdominować percepcję rzeczywistości i warunkować sposób korzystania z niej - wzrok, jako wysoko wartościowany w zachodniej kulturze, często występuje w takiej roli. Szczególnym przykładem utożsamienia wiedzy z widzeniem może być oparta na użyciu szkła architektura, rozwijająca się w kulturze europejskiej od ok. połowy XIX wieku. Faworyzuje ona zmysł wzroku, wykluczając inne doznania zmysłowe, co wpływa na wirtualizację doświadczenia ${ }^{21}$. Także rzeźbę odbiera się za pomocą wzroku, choć

19 Obszerne omówienie zabiegów służących ukazaniu w filmie wewnętrznej perspektywy postaci zawiera praca Roberta Birkholca Podwójna perspektywa. O subiektywizacji zapośredniczonej w filmie, Kraków 2019 (zob. zwłaszcza rozdział Subiektywizacja $w$ filmie).

20 Kwestia związku określonego typu architektury z etapem rozwoju świadomości wzrokowej powraca wielokrotnie w pracy Władysława Strzemińskiego Teoria widzenia, Łódź 2016).

${ }^{21}$ Zob. A. Friedberg, Wirtualne okno. Od Albertiego do Microsoftu, tłum. A. Rejniak-Majewska, M. Pabiś-Orzeszyna, Warszawa 2012. Zob. zwłaszcza rozdział: Przezroczystość, „dematerializacja” i zmierzch perspektywy (tamże obszerna literatura przedmiotu). 
przywołuje ona również wrażenia dotykowe - powoduje to wrażenie, że widzenie jest niewystarczającym sposobem kontaktu z dziełem, co można uznać za polemikę z sensem metafory „wiedza to widzenie”. Możliwość odnalezienia tej przenośnej konstrukcji w sztukach opartych na kodzie innym niż językowy wiąże się z rozpoznaniem w nich systemu umożliwiającego dokonanie na znaczonych elementach operacji semantycznych charakterystycznych dla metafory. Umieszczenie obrazu w polu retoryki postulowało wielu badaczy, żeby wymienić tylko Rolanda Barthes'a ${ }^{22}$, Mieczysława Porębskiego $^{23}$ czy Michała Rusinka ${ }^{24}$. Przywoływali oni przede wszystkim perspektywę semiotyczną, pozwalającą szukać tropów i figur jako operacji na poziomie signifié. Warto jednak zwrócić uwagę, że analizę retoryki wizualnej rozwijano częściej w odniesieniu do przekazów o charakterze użytkowym i perswazyjnym, jak reklama czy design ${ }^{25}$. Ustalenia badaczy wskazują, że „struktury znane z retoryki kodu językowego dostrzeżone zostały także w kodzie obrazowym - i okazało się, że pełnią tam podobną funkcję [...]. I na odwrót: struktury retoryczne obecne w języku mają charakter obrazowy, można je zwizualizować; tekst podszyty jest obrazem, jest obrazowy z natury, to znaczy z retoryki”26. Odnalezienie metafory „wiedza to widzenie" w działach wizualnych umożliwia zarówno ich odbiór poprzez medium wzroku, jak i zdolność do retorycznej organizacji komunikatu.

\section{JAK „WIDZI” MUZYKA?}

Czy jednak możliwe jest istnienie metafory „wiedza to widzenie” w kodach semiotycznych, odnoszących się do doświadczeń innych zmysłów - na

22 R. Barthes, Retoryka obrazu, tłum. Z. Kruszyński, [w:] Ut pictura poesis, red. S. Wysłouch, M. Skwara, Gdańsk 2006.

${ }_{23}$ M. Porębski, Czy metaforę można zobaczyć?, „Teksty” 1980, nr 6.

24 Zob.: M. Rusinek, Retoryka obrazu. Przyczynek do percepcyjnej teorii figur, Gdańsk 2012; idem, Wizualizowalność jako kategoria porządkująca figury retoryczne, [w:] Intersemiotyczność. Literatura wobec innych sztuk (i odwrotnie), red. S. Balbus, A. Hejmej, J. Niedźwiedź, Kraków 2004.

${ }^{25}$ Zob. np. G. Kress, T. van Leeuwen, Reading Images. The Grammar of Visual Design, London-New York 2006.

${ }_{26}$ M. Rusinek, Retoryka obrazu..., s. 49. Na temat retoryki wizualnej zob. zwłaszcza rozdziały: „Metamorfoza”. Słowo, obraz oraz: „Kropla rosy”. Percepcyjna teoria figur. 
przykład w muzyce (niewokalnej)? Jeśli postrzegamy metaforę przede wszystkim jako konstrukcję opartą na operacjach kognitywnych, musimy na to pytanie odpowiedzieć twierdząco ${ }^{27}$. Trzeba tu rozważyć dwie kwestie - po pierwsze: czy możliwe jest ewokowanie widzialności, obrazowości w przekazach opartych na znakach nie percypowanych wzrokowo; po drugie: czy możliwe jest przeniesienie na inne typy percepcji owej, wspominanej przez Arendt, ewidentności poznania, będącej istotą analizowanej metafory.

Wśród badaczy nie ma zgody co do tego, czy można mówić o występowaniu w muzyce (niewokalnej) struktur retorycznych paralelnych wobec tych $\mathrm{w}$ języku${ }^{28}$. Za odejście od ordo naturalis można uznać układy dźwiękowe o określonej strukturze, zdeterminowanej przez nietypowy kształt linii melodycznej bądź zaskakujący układ harmoniczny - tu retoryczność dotyczyłaby samej konstrukcji utworu, bez sięgania do poziomu znaczeń, które są uboższe niż w kodzie werbalnym czy ikonicznym. Stanisław Balbus, analizując za Emilem Benvenistem zdolności semantyczne i syntaktyczne trzech sztuk (literatury, malarstwa i muzyki), wskazuje na muzykę jako system semiotyczny, który nie posiada sam przez się żadnej mocy semantycznej ${ }^{29}$. Kwestia możliwości znaczeniowych muzyki jest przedmiotem sporów badaczy, jednak ich tezy krążą zazwyczaj wokół twierdzenia, że: „[z]rozumienie czy odczucie treści pewnych dzieł muzycznych dotyczy tylko ogólnych zakresów, nie zaś precyzyjnie i jednoznacznie określonych pojęćc" ${ }^{30}$. Wobec tak płynnej semantyczności komunikatów muzycznych zasadne wydaje się pytanie, czy możliwe jest ewokowanie przez nie rzeczywistości wizualnej. Jeżeli jednak założyć, że muzyka może wywoływać określone skojarzenia, mieć wartość symbolu (w tym odwołującego się do

${ }^{27}$ Zob. prezentację interakcyjnej teorii metafory [w:] M. Black, Metafora, tłum. J. Japola, „Pamiętnik Literacki” 1971, nr 3.

28 Zob. E. Schreiber, Metafora jako figura muzyczna. Przegląd stanowisk, „Res Facta Nova: Teksty o Muzyce Współczesnej” 2011, nr 12. Autorka przedstawia tu różne próby ujęcia zagadnienia: rozstrzygnięcia badaczy w znacznym stopniu uwarunkowane są tym, jaka teoria metafory stanowi podstawę rozważań.

${ }_{29}$ S. Balbus, Interdyscyplinarność - Intersemiotyczność - Komparatystyka, [w:] Intersemiotyczność. Literatura wobec innych sztuk..., s. 13.

${ }_{30}$ T. Makowiecki, Poezja a muzyka, [w:] Muzyka w literaturze. Antologia polskich studiów powojennych, red. A. Hejmej, Kraków 2002, s. 19. 
tego, co wizualne), a tak jest chociażby w muzyce programowej, aktualizacja metafory „wiedza to widzenie” wydaje się możliwa.

Mark Johnson i Steve Larson ${ }^{31}$, analizując związane $\mathrm{z}$ muzyką metafory, przekonują, że odbiór muzyki zakorzeniony jest w konceptualizacjach związanych z doświadczeniem ruchu i fizycznej siły, a więc w doznaniach dotykowo-kinetycznych. Przestrzenność muzyki (związana zwłaszcza z metaforą muzycznego krajobrazu) przywołuje wrażenie znajdowania się w określanym miejscu i doświadczania muzyki z jednego z możliwych punktów widzenia (!) - obserwatora lub uczestnika ${ }^{32}$. Autorzy deklarują: "When we speak of music in terms of the »MOVING MUSIC « metaphor, we mean that our experience of a bit of music shares something with our experience of seeing objects move in physical space" ${ }^{33}$. Zwracając uwagę na wielość kinetycznych uwarunkowań w metaforach muzycznych (niekiedy to muzyka stanowi obiekt poruszający się wobec odbiorcy, czasem zaś to odbiorca wędruje przez statyczny krajobraz muzyczny), artykuł pozwala na spekulacje co do możliwości ukazywania się muzyki jako obiektu lub krajobrazu, co przywołuje wrażenia wizualne. Otwiera to możliwość dociekań, jaki mógłby być związek owych doznań, muzycznych powidoków z rodzajem wiedzy przekazywanej odbiorcy przez komunikat muzyczny.

\section{JAK „PATRZÄ” DYSKURSY?}

Stanowiący podstawę metafory „wiedza to widzenie” postulat dobrej widzialności obecny jest w wielu dziedzinach ludzkiej aktywności i wielu dyskursach: naukowym, publicystycznym, artystycznym, w komunikacji medialnej. Wynika to z wysokiego kulturowego statusu wiedzy, rozumianej

31 M. Johnson, S. Larson, Something in the Way She Moves - Metaphors of Musical Motion, „Metaphor and Symbol” 2003, No. 2.

32 Znamienne, że w opisach tak doświadczanej muzyki autorzy używają określeń oznaczających wiedzę/doświadczenia, a odnoszących się do widzenia, a więc uaktualniających metaforę „wiedza to widzenie”, zob. np.: „For example, when music is vie wed as a moving object, its status as metaphorical object gives it an a u r a of permanence. Also, taking the participant perspective within the "MUSICAL LANDSCAPE« introduces strong notions of intentional action within a piece of music" [wyróżnienie W.L.]. Ibidem, s. 73.

33 Ibidem, s. 70. 
nie tylko jako produkt (choć współczesna kultura napędzana jest przez nieustanną konsumpcję informacji), ale też jako znak uprzywilejowania. W nauce jasność wywodu i intersubiektywność wytwarzanej wiedzy są nadal ważnym wymogiem i realizuje się je za pomocą figur retorycznych, także odnoszących się do widzenia. Jeanne Fahnestock w pracy Rhetorical Figures in Science ${ }^{34}$ analizuje, jak użycie różnych figur wpływa na - rozumiany tu zarówno literalnie, jak i metaforycznie - kształt wiedzy. Dążenie do jej „jasności” dotyczy zarówno wyrazistości i przejrzystości komunikatu werbalnego, jak i jakości materiału wizualnego, który powinien dać się objąć jednym rzutem oka i dostarczyć od razu pożądaną informację.

Wysoki status wzroku sprawia, że i w dyskursie naukowym, i w komunikacji społecznej większą siłę mają te informacje, które są wizualizowalne dotyczy to zwłaszcza nowych mediów. „Obrazy niedominujące” ${ }^{35}$, czyli wytworzone poza ogólnie obowiązującą estetyką (niekoniecznie „ładne”, wyraźne, podkreślające status etc.) i poza szeroko rozumianym rynkiem informacyjnym, zazwyczaj pozostają niezauważone, bo nie spełniają współczesnych norm widzialności, nie biorą udziału w medialnym spektaklu. Nakaz widzialności i wizualizacji ${ }^{36}$, połączony z rosnącą nieufnością wobec obrazów i posługujących się nimi mediów, wywołuje biegunowo różne reakcje uczestników komunikacji wizualnej. Z jednej strony jest to sięganie po informacje wizualnie wyraziste, często naruszające czy testujące społeczne normy, albo takie, dla których istnieją ustabilizowane wzorce wizualizacji, z drugiej strony - odwrócenie się od rządzonego taką logiką rynku informacyjno-wizualnego, a więc odrzucenie logiki metafory „wiedza to widzenie”. Kryzys przedstawienia, odnoszący się nie tylko do języka, ale i do innych kodów, położył kres iluzji intersubiektywnej komunikacji, zaś wirtualizujące, odcieleśniające działanie logiki wizualnej skłania do dowartościowania innych rodzajów doświadczenia (np. sztuka interaktywna, instalacja). Unieruchomienie i odizolowanie podmiotu, będące celem analizowanego

${ }^{34}$ J. Fahnestock, Rhetorical Figures in Science, Oxford University Press, 1999.

35 Zob. R. Drozdowski, Obraza na obrazy. Strategie społecznego oporu wobec obrazów dominujących, Poznań 2006.

${ }^{36}$ Na temat roli wizualności w komunikacji zob. też: M. Starakiewicz, Model i metafora. Komunikacja wizualna w humanistyce, koncepcja wizualna: M. Starakiewicz, J. Wojnarowski, Kraków 2019. 
przez Deborda spektaklu, wywołuje sprzeciw w postaci chęci powrotu do mobilności charakterystycznej dla świata poza spektaklem, do przywrócenia sprawczości - zarówno osoby odbierającej komunikat, jak i kodów, mediów czy sztuk zaangażowanych w komunikację.

Przekonanie o znaczącej wartości gromadzenia informacji, także wizualnej, współcześnie poddawane jest krytyce. Jak zauważa Bernd Stiegler: „archiwum to nie tylko miejsce służące do przechowywania, ale także miejsce zapomnienia, wymazywania z pamięci i znikania" ${ }^{37}$. Andrzej Leśniak, komentując charakterystyczną dla sztuki współczesnej „gorączkę archiwum”, czyli fascynację dokumentalnymi projektami na wielką skalę, zauważa, że archiwum z zasady wpisuje się w przemysł pamięci, lecz równocześnie nie pozwala na wytworzenie kontrnarracji ${ }^{38}$, stąd częsta konieczność walki o widzialność osób i problemów pomijanych w medialnym spektaklu ${ }^{39}$. Rosnąca świadomość roli widzialności grup i jednostek oraz narzędzi jej kształtowania (marketing wizualny) skutkuje nieufnością wobec mediów i dyskursów, które się nią posługują. Odrzucenie mediów jako przekaźników, zaś nauki jako źródła wiedzy każe dane, także wizualne, na temat jakiegoś wydarzenia czy zjawiska traktować nie jako poświadczenie ich prawdziwości, a dowód na spisek stojący za fałszowaniem informacji. Można to odczytywać jako odwrócenie metafory „wiedza to widzenie” - mniej widzisz, a więc lepiej wiesz ${ }^{40}$. Znamienne, że nieufność budzi tu i wiedza (ze względu na świadomość jej konstruowalności), jak i media, i dyskursy posługujące się wizualnością.

37 B. Stiegler, Obrazy fotografii. Album metafor fotograficznych, tłum. J. Czudec, Kraków 2009, s. 21.

38 A. Leśniak, Gorączka archiwum, „Szum. Sztuka Polska w Rozszerzonym Polu” 2013, nr 1, s. 70 i wyd. nast.

$39 \mathrm{Na}$ temat niektórych strategii podejmowanych przez twórców posługujących się medium fotografii zob. W. Lipszyc, Totalna porażka. O dwóch projektach fotograficznych, „Studia Litteraria et Historica” 2020, nr 9.

40 A. Deignan, L. Cameron, A Re-examination of UNDERSTANDING IS SEEING, „Journal of Cognitive Semiotics”, Vol. 5, No. 1-2. Współczesne badania metafory „wiedza to widzenie" wskazują, że opisuje ona najczęściej trudność w porozumieniu oraz że ujmuje rozumienie (lub jego brak) jako proces, a nie stan. 
W sztukach określanych jako wizualne, do niedawna zdominowanych przez wzrokowy kontakt $\mathrm{z}$ dziełem, pojawia się (m.in. ze względu na intensyfikację intermedialności) tendencja do, z jednej strony, tematyzowania i kontekstualizowania spojrzenia, z drugiej - do wyzyskiwania braku widzialności jako tematu i narzędzia twórczego. Przykładu takiego działania dostarczają prace Anety Grzeszykowskiej z cyklu Portrety, stanowiące zbiór fotografii portretowych, których pierwowzory nie istnieją. „Wszystkie fizjonomie zostały wykreowane przez artystkę w programie do obróbki zdjęć, przy użyciu różnych fotografii i narzędzi korygujących. Pod względem kompozycyjnym portrety Grzeszykowskiej nawiązują do słynnych fotografii Thomasa Ruffa, w istocie są zaś ich odwrotnością, ze zdumiewającym iluzjonizmem przedstawiają ludzi, w których nieistnienie trudno uwierzyć" ${ }^{41}$. Autorka wykorzystuje napięcie między świadectwem naszych oczu i towarzyszącą pracy informacją, widzeniem i wiedzą. Odbiorca jest tu poddany doświadczeniu niesamowitości, tym dotkliwszej, że obrazem bez przedmiotu, reprezentacją bez odniesienia, jest ludzka twarz, obiekt o szczególnym znaczeniu.

\section{UWAGI KOŃCOWE}

Współcześnie mówić można zarówno o utrzymywaniu się znaczącego wpływu metafory „wiedza to widzenie”, jak i o rosnącej wobec niej nieufności. Powszechność, ale i skrajne zleksykalizowanie metaforyki wizualnej w odniesieniu do wiedzy nie pozwalają wyrokować o jej dalszym losie. Czy omawiana formuła się zużyje ${ }^{42}$, czy wypełni nową treścią, pochodzącą ze współczesnego „pola wizualnego”? Ze względu na charakterystyczną dla dzisiejszej rzeczywistości tekstowej mediatyzację i remediatyzację tekstów kultury oraz przenikanie się różnych dyskursów można oczekiwać, że owa wizualność będzie wykraczać poza doświadczenie odnoszące się tylko do percepcji wzrokowej. Możliwe dzięki językowi zbliżenie doświadczenia zmysłowego i tego, co niezmysłowe, skutkowało rozszerzeniem się zakresu użycia pojęcia - stosowanego wcześniej do określenia jedynie percepcji wzrokowej

${ }^{41}$ Opis pracy ze strony galerii udostępniającej prace artystki: http://rastergallery. com/prace/bez-tytulu-portrety/ [dostęp 11.02.2020].

42 Na temat zużywania metafor zob. S. Sontag, Choroba jako metafora, AIDS i jego metafory, tłum. J. Anders, Kraków 2016, s. 171. 
- na nabywanie wiedzy (podobne procesy, choć o mniejszej wadze dla kultury Zachodu, można wskazać dla wszystkich czasowników oznaczających odbieranie wrażeń zmysłowych). Jednym z efektów utożsamiania widzenia i poznawania stała się zmiana zwrotu w ramach charakterystycznego dla metafory mechanizmu przenoszenia znaczeń (nie: wiedza jest jak widzenie, a: widzenie jest takie, jak wiedza), czego skutkiem był kres dominacji pewnego paradygmatu istotnego dla kultury europejskiej. Współcześnie można mówić o współistnieniu dwóch tendencji w ramach dyskursów związanych ze wzrokiem - wzrokocentrycznej, przyznającej największą wartość jasnej wiedzy i wizualizowalnej informacji, oraz wzrokofobicznej, podważającej wiarę w możliwość powszechnie dostępnej wiedzy zapisanej w obrazach. Jeszcze nie widać, która z nich zwycięży, spodziewać się jednak można przekształcenia i rozszerzenia „pola wizualnego”.

\section{Bibliored.grafia}

Hannah Arendt, Życie umysłu, tłum. H. Buczyńska-Garewicz, R. Piłat, B. Baran, Aletheia, Warszawa 2016.

Stanisław Balbus, Interdyscyplinarność - Intersemiotyczność - Komparatystyka, [w:] Intersemiotyczność. Literatura wobec innych sztuk (i odwrotnie), red. S. Balbus, A. Hejmej, J. Niedźwiedź, Universitas, Kraków 2004.

Roland Barthes, Retoryka obrazu, tłum. Z. Kruszyński, [w:] Ut pictura poesis, red.

S. Wysłouch, M. Skwara, słowo/obraz terytoria, Gdańsk 2006.

Jerzy Bartmiński, Stanisława Niebrzegowska-Bartmińska, Dynamika punktu widzenia

w języku, tekście i dyskursie, [w:] Jerzy Bartmiński, Językowe podstawy obrazu świata, Wydawnictwo UMCS, Lublin 2012.

Robert Birkholc, Podwójna perspektywa. O subiektywizacji zapośredniczonej w filmie, Universitas Kraków 2019.

Max Black, Metafora, przeł. J. Japola, „Pamiętnik Literacki” 1971, nr 3.

Jonathan Crary, Techniques of the Observer. On Vision and Modernity in the Nineteenth Century, MIT Press, Cambridge 1992.

Jonathan Crary, Zawieszenia percepcji. Uwaga, spektakl i kultura nowoczesna, tłum.

Ł. Zaremba, I. Kurz, red. I. Kurz, Wydawnictwo UW, Warszawa 2009.

Alice Deignan, Lynn Cameron, A Re-examination of UNDERSTANDING IS SEEING, "Journal of Cognitive Semiotics”, Vol. 5, No. 1-2.

Teresa Dobrzyńska, Od słowa do sensu. Studia o metaforze, IBL PAN, Warszawa 2012.

Rafał Drozdowski, Obraza na obrazy. Strategie społecznego oporu wobec obrazów dominujących, Wydawnictwo Naukowe UAM, Poznań 2006. 
Umberto Eco, Dzieło otwarte, tłum. J. Gałuszka, L. Eustachiewicz, A. Kreisberg, M. Oleksiuk, Czytelnik, Warszawa 1994.

Jeanne Fahnestock, Rhetorical Figures in Science, Oxford University Press, New York 1999.

Anne Friedberg, Wirtualne okno. Od Albertiego do Microsoftu, tłum. A. RejniakMajewska, M. Pabiś-Orzeszyna, Oficyna Naukowa, Warszawa 2012.

Martin Jay, Downcast Eyes. Denigration of Vision in Twentieth-Century French Thought, University of California Press, Berkeley 1993.

Mark Johnson, Steve Larson, Something in the Way She Moves - Metaphors of Musical Motion, „Metaphor and Symbol” 2003, No. 2.

Gunther Kress, Theo van Leeuwen, Reading Images. The Grammar of Visual Design, Routledge, London-New York 2006.

George Lakoff, Mark Johnson, Metafory w naszym życiu, tłum. T. Krzeszowski, Aletheia, Warszawa 2010.

Andrzej Leśniak, Gorączka archiwum, „Szum. Sztuka Polska w Rozszerzonym Polu” 2013, nr 1 .

Weronika Lipszyc, Przezroczystość widzenia. Metaforyka wizualna i dyskurs wzrokocentryczny, [w:] Przezroczystość w kulturze, red. A. Smaga, B. Pawłowska-Jądrzyk, Wydawnictwo Naukowe UKSW, Warszawa 2020.

Weronika Lipszyc, Totalna porażka. O dwóch projektach fotograficznych, „Studia Litteraria et Historica” 2020, nr 9.

Tadeusz Makowiecki, Poezja a muzyka, [w:] Muzyka w literaturze. Antologia polskich studiów powojennych, red. A. Hejmej, Universitas, Kraków 2002.

Lynda Nead, Akt kobiecy. Sztuka, obscena i seksualność, tłum. E. Franus, Rebis, Poznań 1998.

Anna Pajdzińska, Wrażenia zmysłowe jako podstawa metafor językowych, „Etnolingwistyka” 1996, nr 8.

Mieczysław Porębski, Czy metaforę można zobaczyć?, „Teksty” 1980, nr 6.

Richard Rorty, Filozofia a zwierciadło natury, tłum. M. Szczubiałka, Aletheia, Warszawa 1994.

Michał Rusinek, Retoryka obrazu. Przyczynek do percepcyjnej teorii figur, słowo/obraz terytoria, Gdańsk 2012.

Michał Rusinek, Wizualizowalność jako kategoria porządkująca figury retoryczne, [w:] Intersemiotyczność. Literatura wobec innych sztuk (i odwrotnie), red. S. Balbus, A. Hejmej, J. Niedźwiedź, Universitas, Kraków 2004.

Ewa Schreiber, Metafora jako figura muzyczna. Przeglad stanowisk, „Res Facta Nova: Teksty o Muzyce Współczesnej” 2011, nr 12.

Susan Sontag, Choroba jako metafora, AIDS i jego metafory, tłum. J. Anders, Karakter, Kraków 2016.

Maja Starakiewicz, Model i metafora. Komunikacja wizualna w humanistyce, koncepcja wizualna: Jakub Wojnarowski, Maja Starakiewicz, Ha!art, Kraków 2019. 
Bernd Stiegler, Obrazy fotografii. Album metafor fotograficznych, tłum. J. Czudec, Universitas, Kraków 2009.

Władysław Strzemiński, Teoria widzenia, red. I. Luba, Muzeum Sztuki w Łodzi, Łódź 2016.

Borys Uspieński, Strukturalna wspólnota różnych rodzajów sztuki (na przykładzie malarstwa i literatury), tłum. Z. Zaron, [w:] Semiotyka kultury, wybór i oprac.

E. Janus, M.R. Mayenowa, przedmowa S. Żółkiewski, PIW, Warszawa 1977.

Seweryna Wysłouch, Literatura i semiotyka, PWN, Warszawa 2001.

\section{The Metaphor 'Understanding Is Seeing' in Various Semiotic Systems and Discourses}

The article refers to the presence of the metaphor 'understanding is seeing' in various semiotic systems and discourses, pointing to the dominance of cognitive function of metaphor and the unification of sensory experience and mental cognition within it. Outlined is the context in which the emergence of the identification of knowledge with sight takes place and the establishment of this epistemological metaphor, important for Western culture (an oculocentric discourse). The presence of metaphor in visual arts, polysemiotic arts, and music is analyzed, with the indication of the multisensory nature of perceptual experiences (the perspective of rhetorical research on heterosemiotic cultural phenomena is adopted here). In the further part of the text, the role of metaphor in scientific and artistic discourse and media communication is examined, as well as the perspective of the development of the 'visual field' in the face of wear out of metaphor, the co-presence in culture of oculocentric and oculophobic tendencies, and the digital remediatization of cultural texts.

Keywords: sight, seeing, metaphor, semiotic systems, discourses

Data otrzymania tekstu: 20.04.2021 r.

Data zakończenia procesu recenzyjnego: 4.05.2021 r.

Data akceptacji tekstu do druku: 10.05.2021 r. 